\title{
Lower treatment intensity and poorer survival in metastatic colorectal cancer patients who live alone
}

\author{
N Cavalli-Björkman ${ }^{*, 1}$, C Qvortrup ${ }^{2}$, S Sebjørnsen ${ }^{3}$, P Pfeiffer $^{2}$, T Wentzel-Larsen ${ }^{4,5,6}$, B Glimelius ${ }^{1,7}$ \\ and $\mathrm{H}$ Sorbye $^{3}$
}

'Department of Radiology, Oncology and Radiation Science, Uppsala University, 75185 Uppsala, Sweden; ${ }^{2}$ Department of Oncology, Odense University Hospital, Sdr Boulevard 29, 5000 Odense C, Denmark; ${ }^{3}$ Department of Oncology, Haukeland University Hospital, Jonas Liesvei 65, 502I Bergen, Norway; ${ }^{4}$ Centre for Clinical Research, Haukeland University Hospital, Jonas Liesvei 65, 502 I Bergen, Nonway; ${ }^{5}$ Centre for Child and Adolescent Mental Health, Eastern and Southern Norway, Gullhaug Torg 4B, 0484 Oslo, Norway; ${ }^{6}$ Norwegian Centre for Violence and Traumatic Stress Studies, Kirkeveien 166, bygning 48, 0450 Oslo, Nonway; ' Department of Oncology and Pathology, Karolinska Institutet, 17177 Stockholm, Sweden

\begin{abstract}
BACKGROUND: Socioeconomic status (SES) and social support influences cancer survival. If SES and social support affects cancer treatment has not been thoroughly explored.

METHODS: A cohort consisting of all patients who were initially diagnosed with or who developed metastatic colorectal cancer (mCRC, $n=781$ ) in three Scandinavian university hospitals from October 2003 to August 2006 was set up. Clinical and socioeconomic data were registered prospectively.

RESULTS: Patients living alone more often had synchronous metastases at presentation and were less often treated with combination

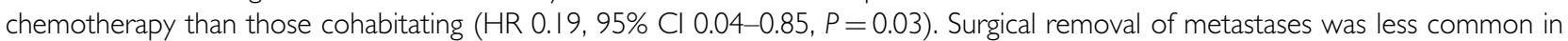
patients living alone ( $\mathrm{HR} 0.29,95 \% \mathrm{Cl} 0.10-0.86, P=0.02)$ but more common among university-educated patients $(\mathrm{HR} 2.22,95 \% \mathrm{Cl}$ I. I 0-4.49, $P=0.02$ ). Smoking, being married and having children did not influence treatment or survival. Median survival was 7.7 months in patients living alone and I I.7 months in patients living with someone $(P<0.00 \mathrm{I})$. Living alone remained a prognostic factor for survival after correction for age and comorbidity.

CONCLUSION: Patients living alone received less combination chemotherapy and less secondary surgery. Living alone is a strong independent risk factor for poor survival in $\mathrm{mCRC}$.

British Journal of Cancer (2012) 107, 189-194. doi:10.1038/bjc.2012.186 www.bjcancer.com
\end{abstract}

Published online 10 May 2012

(c) 2012 Cancer Research UK

Keywords: colorectal cancer; socioeconomic status; education; living alone; social support; comorbidity

A large number of studies have shown that overall and cancerspecific survival is better in individuals with high socioeconomic status (SES) (Bentley et al, 2008; Byers et al, 2008; Halmin et al, 2008; Harris et al, 2009; Aarts et al, 2010; Cavalli-Bjorkman et al, 2011). Socioeconomic status is usually defined by factors such as maximum attained level of education, income (own/family's/neighbourhood's), and overall standard of living (Blais et al, 2006). Although strictly not contributing to SES, social network has been studied in this context and patients with few friends and family members have been shown to have shorter cancer survival than those with a large social sphere (Goodwin et al, 1987; Reynolds et al, 1994; Datta et al, 2009; Chou et al, 2010). In controlled studies on cancer survival, the relative risk for mortality of married respondents was $12 \%$ lower than that of unmarried persons (Pinquart and Duberstein, 2010).

Reasons for poorer outcome in socially deprived patients might be more advanced disease at presentation, comorbidity and treatment-related morbidity (Frederiksen et al, 2009; Hines et al, 2009; Fusco et al, 2010). Difficulty in accessing health care may

\footnotetext{
*Correspondence: Dr N Cavalli-Björkman; E-mail: nina.cavalli-bjorkman@onkologi.uu.se Received I4 February 20 I2; revised 2 April 2012; accepted 9 April 20 I2; published online 10 May 2012
}

also be a factor (Lejeune et al, 2010; Sankaranarayanan et al, 2010; Baade et al, 2011). Proposed explanations for the importance of social support range from psychosocial ones (more meaningful to prolong survival when surrounded by loved ones) to the benefit reaped from practical help during cancer treatment. There is also a possibility that patients with low SES and/or poorer social support are offered different treatment for cancer than more privileged patients (Dobie et al, 2006; Villingshoj et al, 2006; McBride et al, 2010; van Steenbergen et al, 2010). If patients' SES or social situation determines which treatment they are offered the reasons for this need to be more fully understood. In the present study, the setting is Scandinavia, where healthcare is tax financed and freely available to all citizens regardless of social standing. Cancer treatment is exclusively administered at government-funded hospitals and not at private clinics. Treatment guidelines are regularly updated to promote fair and equal treatment for patients of different geographic regions. If treatment were to vary by social standing in Scandinavia, it could mean that doctors take the patient's SES and/or social circumstances into account when designing cancer treatment (Lemmens et al, 2005; Tilney et al, 2009).

The aim of the present study was to explore treatment and survival in a Scandinavian, population-based, cohort of metastatic colorectal cancer (mCRC) patients stratified for indicators of SES and social support. 


\section{MATERIALS AND METHODS}

On 1st October 2003, prospective registration of patients with mCRC referred to oncology units of three university hospitals was initiated. The aim was to use hospitals which received all referrals to an oncology department of that region, that is, hospitals in regions where there was only one oncology department providing radiation therapy and medical treatment for adult cancer patients. Uppsala University Hospital in Sweden serves a region of $\sim 280000$ inhabitants, Odense University Hospital in Denmark serves 475000 and Haukeland University Hospital in Norway 450000 people. All patients in these three areas who need oncologic treatment will be referred to the only university hospital in that region. A cohort consisting of all patients who were initially diagnosed with or who developed metastases from CRC and who were referred to these oncology departments until 1st August 2006 was created.

The cohort consisted of 781 patients, 296 from Norway, 323 from Denmark and 162 from Sweden. All patients had stage IV histologically confirmed adenocarcinoma of the colon or rectum. They completed questionnaires regarding medical history, family structure, maximum level of attained education and smoking habits at the first consultation. We prospectively recorded clinical characteristics, comorbid conditions, routine blood tests, treatment offered and whether the patient was included in a clinical trial or not. Missing data has been retrospectively retrieved from the patients' files. The cohort was originally set up with the primary intent to study trial inclusion, and the results from this project have been previously published (Sorbye et al, 2009).

\section{Socioeconomic status and social support}

Disease-related factors were tested against five variables: marriage/ cohabitation with a partner, having children, living alone, smoking and maximum level of education. The first four variables were answered by either 'yes' or 'no', whereas educational level was split in two groups: maximum level 12 years of school (non-university), and university or the equivalent. In Scandinavia cohabitation, without being married, is common and for the purpose of this study cohabitation with a partner is considered equal to marriage. Married patients were further divided by sex, as it had been reported that men and women benefit differently from the educational level of their spouse (Jaffe et al, 2006).

\section{Other variables}

Co-morbidity was sub-classified into diabetes, cardiovascular, pulmonary and psychiatric, but for the purpose of these analyses only division into comorbidity/ no comorbidity was used. In a Dutch colon cancer study, further subdivision of comorbidity according to a modified Charlson classification did not improve the interpretation of comorbidity data (Lemmens et al, 2005). The patients were divided into two groups: those with metastatic disease at presentation (synchronous metastases) and those who had developed metastases after initially having had localised disease (metachronous metastases). If metastases were found within 90 days of the initial diagnosis, the patient was considered to have synchronous metastases. At the patients' first consultation, performance status (PS) was scored using the WHO classification and patients were divided into four groups: PS 0, 1, 2 and 3-4. The latter were grouped together as they constitute patients generally considered ineligible for palliative chemotherapy. Combination chemotherapy, that is, an irinotecan or oxaliplatin combination with 5-fluorouracil (5-FU), was administered to 350 patients (Table 1). Bevacizumab and cetuximab were grouped together under 'antibody treatment'. Some cohort patients $(n=55)$ were included in the randomised Nordic VII trial, where 2 out of 3 of patients were given cetuximab as first-line treatment. As trial inclusion was a factor to be analysed, we chose to limit the
Table I Patient characteristics of all registered patients $(n=78 \mathrm{I})$

\begin{tabular}{|c|c|c|c|}
\hline & $n$ & $\%$ & Missing, $n$ \\
\hline Median age & 71 (22-95) & & 0 \\
\hline $\begin{array}{l}\text { Gender } \\
\text { Male } \\
\text { Female }\end{array}$ & $\begin{array}{l}414 \\
367\end{array}$ & $\begin{array}{l}53 \\
47\end{array}$ & 0 \\
\hline $\begin{array}{l}\text { Type of metastasising } \\
\text { Synchronous metastases } \\
\text { Metachronous metastases }\end{array}$ & $\begin{array}{l}433 \\
348\end{array}$ & $\begin{array}{l}55 \\
45\end{array}$ & 0 \\
\hline Colon primary & 521 & 67 & 0 \\
\hline Surgery of primary tumour & 570 & 73 & 0 \\
\hline $\begin{array}{l}\text { Performance status, WHO } \\
0 \\
1 \\
2 \\
3+4\end{array}$ & $\begin{array}{l}253 \\
217 \\
156 \\
138\end{array}$ & $\begin{array}{l}32 \\
28 \\
20 \\
18\end{array}$ & 17 \\
\hline $\begin{array}{l}\text { Comorbid conditions } \\
\text { With comorbidity } \\
\text { Without comorbidity }\end{array}$ & $\begin{array}{l}443 \\
330\end{array}$ & $\begin{array}{l}57 \\
42\end{array}$ & 8 \\
\hline $\begin{array}{l}\text { Marital status } \\
\text { Married/cohabitating } \\
\text { Single }\end{array}$ & $\begin{array}{l}517 \\
253\end{array}$ & $\begin{array}{l}66 \\
32\end{array}$ & 11 \\
\hline $\begin{array}{l}\text { Parenting } \\
\text { Patients with children } \\
\text { Patients without children }\end{array}$ & $\begin{array}{c}661 \\
98\end{array}$ & $\begin{array}{l}85 \\
13\end{array}$ & 22 \\
\hline $\begin{array}{l}\text { Living arrangements } \\
\text { Living alone } \\
\text { Living with someone }\end{array}$ & $\begin{array}{l}245 \\
523\end{array}$ & $\begin{array}{l}31 \\
67\end{array}$ & 13 \\
\hline $\begin{array}{l}\text { Smoking status } \\
\text { Smokers } \\
\text { Non-smokers }\end{array}$ & $\begin{array}{l}178 \\
528\end{array}$ & $\begin{array}{l}23 \\
68\end{array}$ & 75 \\
\hline $\begin{array}{l}\text { Educational level } \\
\text { Non-university } \\
\text { University }\end{array}$ & $\begin{array}{c}574 \\
93\end{array}$ & $\begin{array}{l}73 \\
12\end{array}$ & 114 \\
\hline $\begin{array}{l}\text { Oncological treatment } \\
\text { Active treatment } \\
\text { Combination chemotherapy } \\
\text { Best supportive care }\end{array}$ & $\begin{array}{l}465 \\
350 \\
315\end{array}$ & $\begin{array}{l}60 \\
45 \\
40\end{array}$ & I \\
\hline $\begin{array}{l}\text { Antibody treatment } \\
\text { Treated with cetuximab } \\
\text { Not treated with cetuximab } \\
\text { Treated with bevacizumab } \\
\text { Not treated with bevacizumab }\end{array}$ & $\begin{array}{l}108 \\
673 \\
49 \\
732\end{array}$ & $\begin{array}{r}14 \\
86 \\
6 \\
94\end{array}$ & 0 \\
\hline $\begin{array}{l}\text { Secondary surgery } \\
\text { Surgical removal of metastases } \\
\text { No secondary surgery }\end{array}$ & $\begin{array}{c}49 \\
725\end{array}$ & $\begin{array}{r}6 \\
93\end{array}$ & 7 \\
\hline $\begin{array}{l}\text { Clinical trial participation } \\
\text { Trial inclusion } \\
\text { No trial inclusion }\end{array}$ & $\begin{array}{l}169 \\
611\end{array}$ & $\begin{array}{l}22 \\
78\end{array}$ & 1 \\
\hline
\end{tabular}

antibody group to patients treated outside of a clinical trial Patients over the age of 75 were excluded from analyses on antibody treatment and secondary surgery as novel treatments were rarely used for elderly patients during this time frame. Data on age and comorbidity were used to adjust results.

\section{Statistical methods}

As the numbers of events in some categories were few, statistical analysis had to be adjusted. Combination chemotherapy, administered to 350 patients, was compared with the 100 patients receiving only 5-FU. The smallest group in this category limited the statistical model, which led to omission of analysis on possible 
Treatment and survival of cancer patients who live alone

Table 2 Multivariate analyses (ordinal regression) of disease characteristics and treatment by education and family structure

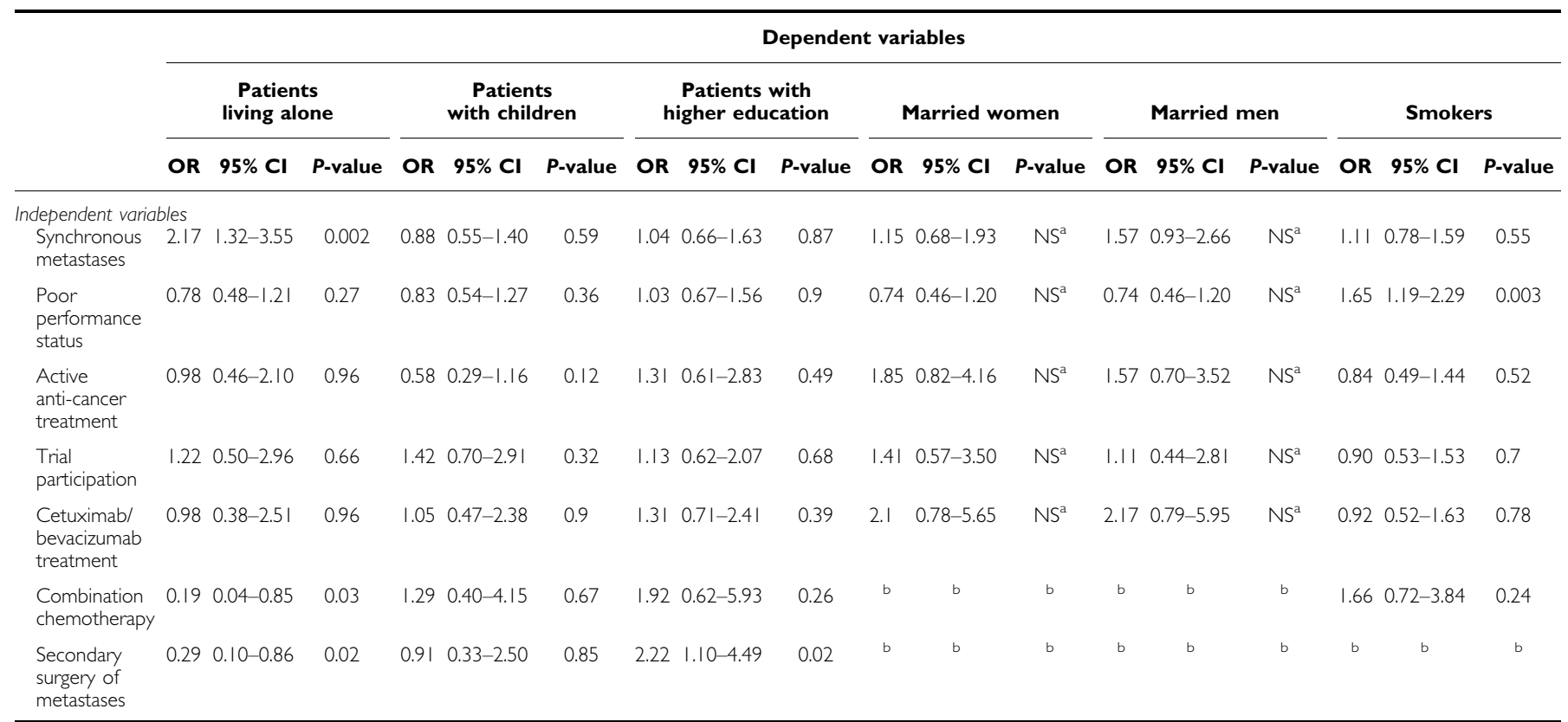

Abbreviations: $\mathrm{Cl}=$ confidence interval; $\mathrm{NS}=$ not significant; $\mathrm{OR}=$ odds ratio. Adjustment for age and comorbidity done in all analyses. ${ }^{\mathrm{a} A n a l y s i s ~ n o t ~ d o n e ~ f o r ~ m a r r i e d ~ m e n ~ a n d ~}$ women separately as overall value was not statistically significant. ${ }^{b}$ Analysis not done due to small number of patients in analysis.

effects on marital status. The smallest group treated (49 patients) was the group who had secondary surgery for metastases and the number of factors, which we could test with accuracy, were calculated to be three. For multivariate analyses in Table 2, the analyses for secondary surgery had to be limited to living alone, having children and educational level. Logistic regression was used for dichotomous and ordinal logistic regression for ordinal outcome variables, with multiple imputations to reduce loss of data due to missing values in the covariates. Two group comparisons were performed using exact chi-square tests for dichotomous or nominal variables, exact Mann-Whitney tests for ordinal variables, and Student $t$-tests for continuous variables. Overall survival analyses for all patients were performed for the time interval from the date of non-resectable metastatic disease to the date of death or censored if the patient was alive on 15 August 2008, using the Kaplan-Meier method with log-rank tests for univariate and Cox regression for multivariate analyses. Overall, rather than cancer-specific, survival was opted for since it was of interest to study influence of comorbidity on treatment and survival. A separate Cox regression analysis was done to deduce possible confounding effects of high age and comorbidity on survival in patients living alone. The proportional hazard assumptions were checked as recommended by Therneau and Grambsch, 2000.

All analyses were performed with the statistical programme: $\mathrm{R}$ version 2.10.0 (The $\mathrm{R}$ Foundation for Statistical Computing, Vienna, Austria), using the $\mathrm{R}$ package rms for regression analyses. The function aregImpute in the $\mathrm{R}$ package Hmisc functions was used for multiple imputations (200 imputed data sets). level.

All statistical tests were two tailed, using the 5\% significance

\section{RESULTS}

\section{Patient characteristics}

Baseline patient characteristics of all registered patients in the cohort are shown in Table 1. As the cohort was population-based and patients were consecutively included, a large percentage of patients were older and had poor performance status. More than half of the patients had significant comorbid conditions, as judged by the attending physicians.

\section{Disease characteristics and treatment}

Table 2 shows results of multivariate analyses with adjustment for age and comorbidity. Patients who lived alone more often presented with metastatic disease than those who lived with someone (OR 2.17, 95\% CI 1.32-3.55) and were less often treated with combination chemotherapy (OR $0.19,95 \%$ CI $0.04-0.85$ ) and secondary surgery of metastases (OR 0.29 , 95\% CI $0.10-0.86$ ). Patients with university education more often had surgery of metastases than patients with non-university education (OR 2.22, 95\% CI 1.10-4.49). Smokers had poorer PS than non-smokers at baseline (OR 1.65, 95\% CI 1.19-2.29). No differences in disease stage, PS and treatment given were seen with respect to marital status and having children. With the exception of surgery for liver or lung metastases, educational attainment did not influence treatment.

\section{Survival}

Median survival times stratified by educational level, comorbidity and indicators of social support are shown in Table 3. Differences in overall survival were seen between patients living alone and those living with someone ( $7.7 v s 11.7$ months, $P<0.001$ ). Similar survival differences were seen between patients with and without comorbidity $(8.0$ vs 12.5 months, $P=0.01)$. No significant differences in survival were seen with regard to smoking, marital status, educational level and having children. Cox regression analysis showed that living alone (HR 1.19, 95\% CI 1.01-1.41, $P=0.03$ ) and higher age (HR 1.03, 95\% CI 1.02-1.03, $P<0.001$ ) were independent prognostic factors for survival, whereas comorbidity was not. When checking proportional hazard assumptions, the global test showed significant deviations $(P<0.001)$. No deviations were indicated for living alone $(P=0.208)$, but for both adjustments variables age $(P<0.001)$ 
Table 3 Median overall survival in different patient groups

\begin{tabular}{|c|c|c|}
\hline & Months $(95 \% \mathrm{Cl})$ & P-value (log-rank) \\
\hline \multicolumn{3}{|l|}{ Patients living alone } \\
\hline Yes & $7.7(6.3-9.8)$ & \\
\hline No & $11.7(10.3-13.1)$ & $<0.001$ \\
\hline \multicolumn{3}{|l|}{ Patients with children } \\
\hline Yes & $10.5(9-11.6)$ & \\
\hline No & $9.3(7.1-12.4)$ & 0.451 \\
\hline \multicolumn{3}{|c|}{ Patients with higher education } \\
\hline Yes & $11.5(9.1-15.2)$ & \\
\hline No & $11.2(9.5-12.4)$ & 0.574 \\
\hline \multicolumn{3}{|c|}{ Patients with comorbidity } \\
\hline Yes & $8.0(6.7-10)$ & \\
\hline No & $12.5(11.3-14.8)$ & 0.009 \\
\hline \multicolumn{3}{|l|}{ Marital status } \\
\hline Married women & $12.5(10.4-15.4)$ & \\
\hline Married men & $11.2(8.6-13.2)$ & 0.216 \\
\hline \multicolumn{3}{|l|}{ Smokers } \\
\hline Yes & $8.3(5.9-12.8)$ & \\
\hline No & $10.9(9.3-11.9)$ & 0.349 \\
\hline
\end{tabular}

Abbreviation: $\mathrm{Cl}=$ confidence interval.

and comorbidity $(P=0.012)$. Plots of Schoenfeld residuals indicated that age may be less influential as the disease progresses while comorbidity may be a risk factor around the time of diagnosis of mCRC.

\section{DISCUSSION}

In this population-based $\mathrm{mCRC}$ cohort, patients who lived alone had more advanced disease at presentation were less likely to receive potent combination chemotherapy regimens and had poorer survival than those who lived with someone. As data has been adjusted for age and comorbidity, it is not possible to explain the above by hypothesising that patients who live alone are old and frail with poor PS. Reports that focus on treatment of cancer patients who live alone are scarce. In an American study on survival of head-neck cancer patients, men without a partner were found to have considerably shorter survival even after controlling for disease variables (Konski et al, 2006). Other studies have found that patients with Non-Hodgkin lymphoma (Frederiksen et al, 2011) and lung cancer (Dalton et al, 2011) present with later stages of their respective diseases if they live alone than if they live with someone. To our knowledge, it has not been shown previously that lowered treatment intensity might be a contributing factor to the shorter survival of patients who live alone. This is of concern because of the large number of people who live by themselves - a phenomenon which is becoming increasingly common, especially in urban areas.

It is reasonable to speculate that the absence of a partner can delay diagnosis as the patient lacks the social support needed to actively pursue medical help. It is also possible that these patients may be, consciously or subconsciously, judged by physicians as being without the support to qualify them for more intensive oncologic treatment. Knowing that patients have strong networks enables clinicians to risk treatment with potentially serious side-effects. Further, the choice between undergoing potentially life-prolonging treatment while sometimes enduring considerable toxicity, or declining treatment, has to be made by the patient. We cannot rule out the possibility that the will to have such treatment is stronger in patients who live with someone than it is in those who do not.

Colorectal cancer treatment has developed immensely in the last decade. In the 1980s it was not certain that mCRC patients had any benefit from chemotherapy at all. A few studies subsequently showed that 5-FU alone gave slightly prolonged survival, and in the 1990s addition of oxaliplatin and irinotecan improved survival even more (Glimelius and Cavalli-Bjorkman, 2012). As it is clear that combining 5-FU with oxaliplatin or irinotecan prolongs survival, we must see a connection between patients living alone receiving less combination chemotherapy and having shorter survival.

During the time frame that the cohort in this study was set up, targeted drugs in the form of antibodies were tested, mainly within the confines of clinical trials. The three Scandinavian countries have very similar treatment guidelines for mCRC patients. If the patient's PS is good enough patients in all three countries will be recommended to receive sequential treatment of 5-FU, oxaliplatin and irinotecan, in different combinations and different orders, provided toxicity is acceptable and the disease responds favourably. In some instances, antibody will be added. The only difference between the countries is that Norway does not generally recommend palliative chemotherapy for patients over the age of 75. In our cohort, patients over this age were excluded from analysis and results were thus not affected by this.

Marital status has previously been studied and as a marker for social support some groups have found advantages for married patients with regard to cancer survival (Patel et al, 2010). We were not able to verify this in our material. However, being married is not always the same as living with someone. In large register studies, married patients may be perceived as having good family support. In our cohort, some patients were married but lived apart as the spouse was in a nursing home. We also included patients living with their adult children into the group of cohabitating patients as we felt this reflected a dimension of social support. An individual evaluation of the patients' living arrangements, as was possible in this prospectively collected cohort, is likely to be a more accurate way to study the effect of social support than to simply look at marital status.

Having children can mean different things to different people when relationships with offspring are close it means increased social support, but not all people remain in contact with adult children. Because of this discrepancy, having children, as an SES parameter, is probably not very reliable in indicating good network and support. Having a live-in-partner is more likely to be indicative of solid family structure in this sense.

Maximum attained educational level has traditionally been used as a strong indicator of SES. In the Scandinavian countries it is more likely to reflect SES than income or area of residence and has been used in a number of studies on cancer and SES (Eaker et al, 2009; Berglund et al, 2010). When using social databases to extract information on occupation, employment status, income and socioeconomic index, all factors have followed the trend set by educational level (Eaker et al, 2009; Cavalli-Bjorkman et al, 2011). Register studies in Scandinavia and elsewhere have shown that there are differences in diagnostic activity, treatment and survival by educational level (Halmin et al, 2008). One major drawback in a number of these studies has been the lack of information on comorbidity (Halmin et al, 2008; Cavalli-Bjorkman et al, 2011). There is strong evidence that the prevalence of comorbid conditions is higher in groups with lower SES (Louwman et al, 2010). Many studies on SES and cancer have been inconclusive as data could not be adjusted for comorbidity. Interestingly, in the smaller cohort of patients in the present study we could not verify differences by educational level with the exception of secondary surgery for distant metastases. It is possible that this is because we have the advantage of detailed information on patients' comorbidity and we have been able to adjust for this. We have, on 773 patients in the cohort (99\%), scored and sub-classified 
comorbidity from an oncologists' point of view. As some comorbidity contraindicates chemotherapy while other diseases do not, this is an asset in the present study.

Compared with other countries' treatment frequencies, some of the percentages in this study can seem low. Secondary curative surgery, for instance, is usually reported to be performed in $10-15 \%$ of the patients, whereas in our study the number was $6 \%$. As this cohort is population based and includes all consecutive patients with $\mathrm{mCRC}$, it well represents the general population of stage IV CRC patients. In this cohort treatment and outcome are poorer than in clinical trials, where patients often are highly selected. Almost $20 \%$ of patients presented with PS 3 or worse, automatically disqualifying them from chemotherapy, and many patients were elderly. Overall survival is also much shorter than in other patient series. Again this reflects the population-based nature of the patient material; overall survival in patients treated with combination therapy or in a clinical trial was similar to all other series, or close to 2 years (Sorbye et al, 2009). Bevacizumab treatment was quite rare in this cohort. This is best explained by the clinical trials that were ongoing during the years 2003-2006. The trials, in all three countries, recruited more patients to treatment with cetuximab than bevacizumab. During this time frame patients were not selected for treatment with cetuximab based on their K-ras-status.

In Scandinavia regional oncologic centres work towards equal treatment for all patients regardless of background and place of habitation. National guidelines approved by the National Health authorities for both adjuvant and palliative treatment are produced in conjunction with these centres. This may in itself lessen the risk of unequal treatment, and many clinicians feel that inequality in the public health care sector is not a prevailing problem. We did not find significant differences between patients of different educational level and social situation with the exception of patients living alone. This is an interesting finding which deserves attention as it may be a factor which subconsciously influences the decisions made by oncologists for cancer patients. If patients can be offered better support, it may be possible to increase treatment intensity and prolong survival in this group.

\section{ACKNOWLEDGEMENTS}

This study has been supported by the Swedish, Norwegian and Danish Cancer Societies and the Stockholm Cancer Society. This study was approved by the ethical committees in each country, and was conducted in accordance with the declaration of Helsinki. We thank Randi Eikeland (Clinical Cancer Research Office, Haukeland University Hospital, Bergen, Norway) for data managing, Mari Holsen (Deptartment of Oncology, Haukeland University Hospital, Bergen, Norway), Marie Rosén (Akademiska University Hospital, Uppsala, Sweden) and their colleagues in Odense for contributing to collection of data.

\section{REFERENCES}

Aarts MJ, Lemmens VE, Louwman MW, Kunst AE, Coebergh JW (2010) Socioeconomic status and changing inequalities in colorectal cancer? A review of the associations with risk, treatment and outcome. Eur J Cancer 46: 2681-2695

Baade PD, Dasgupta P, Aitken JF, Turrell G (2011) Distance to the closest radiotherapy facility and survival after a diagnosis of rectal cancer in Queensland. Med J Aust 195: 350-354

Bentley R, Kavanagh AM, Subramanian SV, Turrell G (2008) Area disadvantage, individual socio-economic position, and premature cancer mortality in Australia 1998 to 2000: a multilevel analysis. Cancer Causes Control 19: 183-193

Berglund A, Holmberg L, Tishelman C, Wagenius G, Eaker S, Lambe M (2010) Social inequalities in non-small cell lung cancer management and survival: a population-based study in central Sweden. Thorax 65: $327-333$

Blais S, Dejardin O, Boutreux S, Launoy G (2006) Social determinants of access to reference care centres for patients with colorectal cancer-a multilevel analysis. Eur J Cancer 42: 3041-3048

Byers TE, Wolf HJ, Bauer KR, Bolick-Aldrich S, Chen VW, Finch JL, Fulton JP, Schymura MJ, Shen T, Van Heest S, Yin X (2008) The impact of socioeconomic status on survival after cancer in the United States: findings from the National Program of Cancer Registries Patterns of Care Study. Cancer 113: 582-591

Cavalli-Bjorkman N, Lambe M, Eaker S, Sandin F, Glimelius B (2011) Differences according to educational level in the management and survival of colorectal cancer in Sweden. Eur J Cancer 47: 1398-1406

Chou AF, Stewart SL, Wild RC, Bloom JR (2010) Social support and survival in young women with breast carcinoma. Psychooncology

Dalton SO, Frederiksen BL, Jacobsen E, Steding-Jessen M, Osterlind K, Schuz J, Osler M, Johansen C (2011) Socioeconomic position, stage of lung cancer and time between referral and diagnosis in Denmark, 2001-2008. Br J Cancer 105: 1042-1048

Datta GD, Neville BA, Kawachi I, Datta NS, Earle CC (2009) Marital status and survival following bladder cancer. J Epidemiol Community Health 63: $807-813$

Dobie SA, Baldwin LM, Dominitz JA, Matthews B, Billingsley K, Barlow W (2006) Completion of therapy by Medicare patients with stage III colon cancer. J Natl Cancer Inst 98: 610-619

Eaker S, Halmin M, Bellocco R, Bergkvist L, Ahlgren J, Holmberg L, Lambe $M$ (2009) Social differences in breast cancer survival in relation to patient management within a National Health Care System (Sweden). Int $J$ Cancer 124: $180-187$
Frederiksen BL, Brown Pde N, Dalton SO, Steding-Jessen M, Osler M (2011) Socioeconomic inequalities in prognostic markers of non-Hodgkin lymphoma: analysis of a national clinical database. Eur J Cancer 47: 910-917

Frederiksen BL, Osler M, Harling H, Ladelund S, Jorgensen T (2009) Do patient characteristics, disease, or treatment explain social inequality in survival from colorectal cancer? Soc Sci Med 69: $1107-1115$

Fusco M, Pezzi A, Benatti P, Roncucci L, Chiodini P, Di Maio G, Di Napoli R, de Leon MP (2010) Clinical features and colorectal cancer survival: an attempt to explain differences between two different Italian regions. Eur J Cancer 46: 142-149

Glimelius B, Cavalli-Bjorkman N (2012) Metastatic colorectal cancer: Current treatment and future options for improved survival Medical approach-present status. Scand J Gastroenterol 47: 296-314

Goodwin JS, Hunt WC, Key CR, Samet JM (1987) The effect of marital status on stage, treatment, and survival of cancer patients. JAMA 258: 3125-3130

Halmin M, Bellocco R, Lagerlund M, Karlsson P, Tejler G, Lambe M (2008) Long-term inequalities in breast cancer survival-a ten year follow-up study of patients managed within a National Health Care System (Sweden). Acta Oncol 47: 216-224

Harris AR, Bowley DM, Stannard A, Kurrimboccus S, Geh JI, Karandikar S (2009) Socioeconomic deprivation adversely affects survival of patients with rectal cancer. Br J Surg 96: 763-768

Hines RB, Chatla C, Bumpers HL, Waterbor JW, McGwin Jr G, Funkhouser E, Coffey CS, Posey J, Manne U (2009) Predictive capacity of three comorbidity indices in estimating mortality after surgery for colon cancer. J Clin Oncol 27: 4339-4345

Jaffe DH, Eisenbach Z, Neumark YD, Manor O (2006) Effects of husbands' and wives' education on each other's mortality. Soc Sci Med 62: 2014-2023

Konski AA, Pajak TF, Movsas B, Coyne J, Harris J, Gwede C, Garden A, Spencer S, Jones C, Watkins-Bruner D (2006) Disadvantage of men living alone participating in Radiation Therapy Oncology Group head and neck trials. J Clin Oncol 24: 4177-4183

Lejeune C, Sassi F, Ellis L, Godward S, Mak V, Day M, Rachet B (2010) Socio-economic disparities in access to treatment and their impact on colorectal cancer survival. Int J Epidemiol 39: 710-717

Lemmens VE, van Halteren AH, Janssen-Heijnen ML, Vreugdenhil G, Repelaer van Driel OJ, Coebergh JW (2005) Adjuvant treatment for elderly patients with stage III colon cancer in the southern Netherlands is 
Treatment and survival of cancer patients who live alone N Cavalli-Björkman et al

affected by socioeconomic status, gender, and comorbidity. Ann Oncol 16: 767-772

Louwman WJ, Aarts MJ, Houterman S, van Lenthe FJ, Coebergh JW, Janssen-Heijnen ML (2010) A 50\% higher prevalence of life-shortening chronic conditions among cancer patients with low socioeconomic status. Br J Cancer 103: 1742-1748

McBride RB, Lebwohl B, Hershman DL, Neugut AI (2010) Impact of socioeconomic status on extent of lymph node dissection for colon cancer. Cancer Epidemiol Biomarkers Prev 19: 738-745

Patel MK, Patel DA, Lu M, Elshaikh MA, Munkarah A, Movsas B (2010) Impact of marital status on survival among women with invasive cervical cancer: analysis of population-based surveillance, epidemiology, and end results data. J Low Genit Tract Dis 14: 329-338

Pinquart M, Duberstein PR (2010) Associations of social networks with cancer mortality: a meta-analysis. Crit Rev Oncol Hematol 75: 122-137

Reynolds P, Boyd PT, Blacklow RS, Jackson JS, Greenberg RS, Austin DF, Chen VW, Edwards BK (1994) The relationship between social ties and survival among black and white breast cancer patients. National Cancer Institute Black/White Cancer Survival Study Group. Cancer Epidemiol Biomarkers Prev 3: 253-259
Sankaranarayanan J, Watanabe-Galloway S, Sun J, Qiu F, Boilesen EC, Thorson AG (2010) Age and rural residence effects on accessing colorectal cancer treatments: a registry study. Am J Manag Care 16: 265-273

Sorbye H, Pfeiffer P, Cavalli-Bjorkman N, Qvortrup C, Holsen MH, Wentzel-Larsen T, Glimelius B (2009) Clinical trial enrollment, patient characteristics, and survival differences in prospectively registered metastatic colorectal cancer patients. Cancer 115: 4679-4687

Therneau T, Grambsch P (2000) Modelling Survival Data: Extending the Cox Model. Springer: New York (NY)

Tilney H, Lovegrove RE, Smith JJ, Thompson MR, Tekkis PP (2009) The National Bowel Cancer Project: social deprivation is an independent predictor of nonrestorative rectal cancer surgery. Dis Colon Rectum 52: 1046-1053

van Steenbergen LN, Rutten HJ, Creemers GJ, Pruijt JF, Coebergh JW, Lemmens VE (2010) Large age and hospital-dependent variation in administration of adjuvant chemotherapy for stage III colon cancer in southern Netherlands. Ann Oncol 21: 1273-1278

Villingshoj M, Ross L, Thomsen BL, Johansen C (2006) Does marital status and altered contact with the social network predict colorectal cancer survival? Eur J Cancer 42: 3022-3027

This work is published under the standard license to publish agreement. After 12 months the work will become freely available and the license terms will switch to a Creative Commons Attribution-NonCommercial-Share Alike 3.0 Unported License. 